\title{
Varieties of Recursivity in Transnational Governance
}

Article by an MPIfG researcher

Olga Malets, Sigrid Quack: Varieties of Recursivity in Transnational Governance. In: Global Policy 8(3), 333-342 (2017). Wiley-Blackwell

The original publication is available at the publisher's web site: https://doi.org/10.1111/1758-5899.12467

Olga Malets

University of Freiburg Sigrid Quack University of Duisburg-Essen

\section{Abstract}

This special section analyzes the variety of recursivity in transnational regulatory governance. We conceptualize recursivity as a complex cycle through which addressees' response to transnational rules continuously feeds back into the rulemaking process and triggers rule revision. In the introduction to the special section, we emphasize that recursivity varies across governance organizations and governance fields and develop an analytical framework to capture this variation. We also propose a typology of recursive governance organizations. Finally, we preview five case studies included in the special section and summarize their key findings and conclusions, with particular attention to the implications for accountability and legitimacy.

\section{Policy implications}

- In order to enhance their accountability and legitimacy, transnational governance organizations should establish formal or informal structures and procedures for collecting and processing regulatory addressees' feedback on the implementation and impact of transnational rules and standards.

- Whether they design formal feedback arrangements or rely on informal feedback from regulatory addressees and other actors, transnational regulatory organizations should monitor and periodically review who uses them, and how, to avoid privileging certain groups over others.

- In order to promote their own responsiveness and accountability, transnational regulatory organizations should develop formal rules or informal mechanisms to reflect on how feedback from addressees is taken into consideration (or not) and how it influences the revision of rules.

This special section contributes to debates in the transnational governance literature on the relationship between regulators and regulatory addressees. Building on a growing literature, we emphasize the importance of understanding feedback effects in transnational governance and focus specifically on how the usage and implementation of rules by their addressees feeds back into rulemaking. In order to capture theoretically the relationship between regulators, regulatory addressees and other groups of actors affected by voluntary rules or involved in monitoring the making and implementation of those rules, we use and expand the concept of recursivity. This concept emphasizes the cyclical and recursive nature of rulemaking and reciprocal linkages between the making of transnational rules and their use and implementation in different contexts.

Since the 1980s, the number and variety of transnational governance arrangements have exploded (Djelic and SahlinAndersson, 2006). Transnational standard-setters, certification schemes and corporate social responsibility initiatives, to name just a few, have become important regulators in many global policy fields, including environment protection, labor and human rights, finance, trade, and security. A characteristic feature of this 'remarkable period of institutional innovation in transnational governance' (Hale and Held, 2010, p. 1) is that non-governmental actors, both from business and civil society, play a much more important role as regulators on a transnational scale than was the case in multilateral state governance. Such transnational governance arrangements typically regulate through voluntary standards, codes of conducts and other forms of so-called 'soft law' that promote changes in behavior of addressees who are under no legal obligation to use and implement them (Black, 2008; Djelic and Sahlin-Andersson, 2006). Nevertheless, their impact is often far-reaching because such rules may become collectively binding in a given policy field through isomorphic pressures and/or ex post recognition by international organizations and states (Green, 2014; Quack, 2007; Tamm Hallström, 2004). ${ }^{1}$

The fact that voluntary rules become collectively binding raises a question of legitimacy, broadly defined as the acceptance of rules by their addressees and other actors as relevant, appropriate and beneficial. Many scholars argue that transnational governance organizations develop various strategies to promote the legitimacy of their rules in this 
sense (Black, 2008; Loconto and Fouilleux, 2014; Tamm Hallström, 2004; Tamm Hallström and Boström, 2010). Participation by rule addressees, affected parties and broader publics who have a stake in transnational rulemaking is recognized as one of the core strategies to generate legitimacy. But participation is not limited to the establishment of rules. Another body of transnational governance literature focuses on the role of addressees and other stakeholders in the continuous revision of regulation, driven by a mismatch between transnational rules and the context in which they are implemented (Botzem and Dobusch, 2012; Halliday and Carruthers, 2007, 2009; Halliday and Shaffer, 2015). This literature emphasizes the cyclical and recursive nature of transnational rulemaking and the growing importance of feedback from regulatory addressees and other stakeholders on rule implementation for transnational governance processes. ${ }^{2}$ Finally, the transnational governance literature suggests that under conditions of growing global economic and political interdependence, the emergence of polycentric governance regimes and strategic uncertainty about governance goals and the means to achieve them, recursive rulemaking responsive to feedback is expected to generate more flexible, legitimate and effective regulation than traditional top-down command and control approaches to governance (Black, 2008; Sabel and Zeitlin, 2012).

Given the theoretical importance of feedback and responsiveness in transnational governance, our empirical knowledge about when and how feedback from the use and implementation of rules is channeled back into transnational rulemaking and under what conditions it triggers the revision of rules and the adjustment of governance organizations is limited and fragmented. This special section advances our knowledge of feedback and responsiveness in transnational governance systems in three ways. First, it introduces the concept of recursivity, capturing the interactions between rulemaking, rule use and rule implementation in transnational governance. Second, it demonstrates that recursivity as a phenomenon can take many forms, and it proposes an analytical framework for their empirical analysis. The analytical framework helps identify the variety of recursivity forms across transnational governance systems. It focuses on the design and organization of recursivity channels in governance systems, their usage in practice by different actors and the responsiveness of governance organizations to feedback. The special section also proposes a typology of recursive processes in transnational governance. Third, it presents several empirical case studies applying the recursivity framework to various transnational governance fields, including sustainable forest management, copyright, labor conditions, microfinance and accounting.

\section{Conceptualizing recursivity}

In their work on legal change in the era of globalization, Halliday and Carruthers $(2007,2009)$ develop a concept of recursivity of law in order to capture reciprocal links between the law on the books and the law in practice. They view domestic legal change as driven by the responses of those subject to the law to broad and indeterminate legal norms formally enacted by state actors: responses to formal law trigger legal reforms which in turn generate new responses. Cycles of legal reforms thus oscillate between formal law and law in practice until a new equilibrium is established (Halliday and Carruthers, 2009, p. 363). In times of globalization, Halliday and Carruthers argue, legal change may be influenced by global norm setting by influential global players, such as international organizations, powerful states and clubs of nations. How specifically global legal norms influence national law depends on recursive processes of national legal change involving domestic lawmakers and implementing actors, such as companies, industrial associations and legal experts. National legal processes are in turn affected by the balance of power between global and national actors and the cultural distance between global norms and the national legal tradition. In a more recent contribution, Halliday and Shaffer (2015) examine recursivity in the context of transnational legal orders where norms are produced in a recognizable legal form by or in conjunction with private actors. Overall, the recursivity of law framework examines formal and legal processes of iterative regulation that are global and transnational in scope.

While it also examines formal procedures, the experimentalist governance framework focuses on deliberative systems of recursive rulemaking. It identifies specific structures, channels and techniques developed by governance organizations to foster experimentation with rule implementation, learning from experience and adjustment of governance goals and means. According to Sabel and Zeitlin (2012), in experimentalist governance architectures, actors agree on broad framework goals and the means to achieve them in a recursive rulemaking process. They can implement these rules flexibly at the national and local level, but commit to reporting their progress and subject themselves to peer review and public comparison. As a result of the review and comparison of implementation experiences and results, governance goals and means are revised collectively to accommodate new problems and opportunities. In addition to peer review, recent experimentalist work also explores other forms of non-hierarchical or joint review. For example, De Búrca (2015) studies the role of NGOs as shadow reporters in UN human rights conventions' review mechanisms. Overdevest and Zeitlin (2014) apply an experimentalist governance framework to global forest governance that includes private, public and hybrid forms of governance and explain how various governance organizations involved in global forest governance interact with each other. In sum, the experimentalist governance approach focuses primarily on formal and deliberative recursivity processes.

While building on these two frameworks, in this special section we develop a more pluralistic approach to recursivity that encompasses informal and emergent arrangements in addition to formal procedures. Our contribution is threefold. First, our focus is on variations in recursivity across governance fields and policy sectors rather than recursivity as such. For instance, Halliday (2009, p. 270) argues that it is a premise of the recursive framework that the exigencies of 
practice affect lawmaking just as the dynamics and structure of lawmaking constrain the shape of subsequent implementation.' We expand this premise by treating recursivity as a variable. The articles in this special section show that recursive processes can take many forms: ranging from formal to informal; involving different actors, such as addressees of regulation, affected groups and broader publics; and providing tight, loose or weak ties between global and local rulemaking and implementation.

Second, we analyze recursivity by design and recursivity in action. Doing so allows us to explore not only how elements of organizational design (i.e. structures and procedures) foster recursive rulemaking, but also whether, how and by whom recursive governance arrangements are actually used (or not) in practice. This applies to both the use of feedback channels by regulatory addressees and affected groups on the one hand, and the actual responsiveness of the regulator to such feedback on the other hand. We also study the responses of groups affected by rules where no or only weak recursivity procedures exist.

Third, the degree of responsiveness of transnational governance schemes cannot be understood without reference to those schemes' embeddedness in wider governance fields or the predominant localization of their addressees in a world and regional perspective. Therefore, each empirical paper not only analyzes the regulatory interactions of transnational regulators, addressees and affected groups within a specific governance scheme, but also takes into account the embeddedness of these interactions in a wider governance field. The fields selected - forest management, copyright, labor, microfinance and accounting - allow us to compare across an unusually broad range of problems, actors and modes of governance. In addition, the articles by Malets on the Forest Stewardship Council, Zajak on the Fair Labor Association and Mader on microfinance schemes address specific country contexts in Russia, China and India, respectively.

In sum, the contributions in this special section demonstrate that procedures for recursive rulemaking can be organized very differently, and that these organizational properties matter for whether and how feedback channels are used by those addressed and affected by transnational governance. Yet highly recursive governance systems depend not only on organizational design, but equally on the structural and cultural contextual factors that facilitate the responsiveness of regulatory addressees, affected groups and publics and the regulator itself.

\section{Analytical framework}

In order to capture the varieties of recursivity in transnational governance, we propose a framework that consists of three elements: (1) the design and organization of recursive procedures; (2) the actual use of feedback channels by regulatory addressees, affected groups and broader publics; and (3) the actual responsiveness to feedback by those in charge of the governance organization. While the first element refers to the design of organizational procedures, be they formal or informal, the second and third elements capture recursivity in action.

\section{Design and organization of recursivity}

All too often, the literature overlooks the fact that transnational governance schemes are organizations. In fact, most of them are set up as non-governmental organizations of some type, and as organizations they have a specific charter, membership rules, organizational structures, management hierarchies and decision-making procedures that are oriented towards their goals as rule or standard setters. Organizations tend to develop coherence in their overall structural patterns and design archetypes (Greenwood and Hinings, 1993). Therefore, structures and procedures for organizing recursivity should be considered in the context of more general features of the organization, such as the degree to which they are membership or supporter-based and expertise or participation-oriented (Anheier and Themudo, 2002). ${ }^{3}$ The organizations studied by the contributors to this special section reflect the range of existing archetypes.

Against this backdrop, two main components of recursivity are of interest for our analysis: procedures for collecting feedback and rules for dealing with it. Procedures for collecting feedback encompass a variety of forms, including consultation, monitoring, evaluation and complaint systems that target different groups of addressees and stakeholders. Rules for dealing with feedback include who is in charge of processing the feedback, whether those providing feedback are given the right to be heard and given an explanation for decisions, who decides about what feedback should be considered or disregarded, and how transparent decisionmaking on feedback is. Substantively, feedback procedures and rules for dealing with feedback can both relate to rulemaking and rule implementation. While calls for consultation on draft standards illustrate the former, complaint channels for problems with implementation exemplify the latter.

We distinguish between formal and informal recursive designs. In organization theory, formal organization is often understood as a normative social system designed by managers, while informal organization often refers to emergent patterns of social interactions between non-managerial members of the organization (Gulati and Puranam, 2009). Another understanding of formal rules is as those rules that are laid down in publicly available documents and prescribe relatively closely how to proceed in everyday practice, while informal rules either are not documented or provide more leeway for flexible adaptation (Koppel, 2010). Formal and informal rules often complement each other in organizations. However, in rulemaking organizations informal decision-making tends to undermine the credibility of formal rules because of its lack of transparency. In this special section, formal organizing refers to procedures that are documented in writing and are transparent to the people involved in recursive processes, while informal organizing refers to procedures that are either not documented in writing or not transparent to those involved. 
Prevalent feedback channels vary in their formalization. Whereas most transnational standard setting organizations conduct public consultations on standards that follow documented rules (Peters et al., 2009; Tamm Hallström, 2004), only a few have developed formal dispute settlement mechanisms (Marx, 2012) and performance monitoring and evaluation systems (Malets, this volume). Informal feedback channels have received significantly less attention in the literature, but online-based communication through public mailing lists in open source communities provides an example (Calliess and Zumbansen, 2010; Dobusch et al., this volume). The formality-informality continuum also applies to the categorization of the groups that are called to provide feedback on draft regulations and implementation problems. In formalized feedback procedures, the addressees are typically exhaustively and clearly listed and described, while in informal procedures who exactly is addressed is often left open. Finally, formality also applies to how those in charge are expected to deal with feedback: to what extent are there written and transparent rules that lay down the right to be heard or given an explanation for decisions, and to what extent is the issue of how to deal with feedback left to the discretion of decision-makers?

In this special section, we suggest that the organization of recursivity in transnational rule and standard setting schemes should be analyzed along the dimensions of the formality and informality of the design. Yet, organizational design alone does not make a governance organization recursive. It is also necessary to analyze who uses feedback channels and how governance organizations respond to the feedback they receive.

\section{Usage of feedback channels}

The availability of various types of feedback channels does not guarantee that those who are expected to use them, that is, the actors implementing, enforcing or monitoring transnational rules and the actors affected by those rules, will actually use these channels to voice their concerns and provide feedback to transnational rule makers. It is therefore critically important to investigate who uses feedback channels, and how, as well as who processes, filters and interprets information that flows through these channels, and how. Although we lack systematic accounts of the patterns of use of feedback channels, several case studies of transnational governance organizations emphasize a range of factors that facilitate and impede the use of such channels. On the one hand, how feedback channels are used depends on their design and the internal organizational rules regulating them. On the other hand, numerous external constraints may limit the ability of users, implementing actors and other groups affected by rules to access feedback channels, both formal and informal. These factors need to be considered in combination with internal rules and other factors shaping who processes and filters information and knowledge entering both formal and informal feedback channels, and how.

For instance, Marx (2014) shows that internal rules for dispute settlement mechanisms in governance organizations may be more or less restrictive in relation to who is able to file a complaint (e.g. anyone or only members of the organization) and which disputes and complaints are accepted as legitimate and investigated and which ones are dismissed. In transnational governance organizations relying on informal feedback channels, a lack of organizational rules and procedures regulating feedback processing and justification of decisions may lead to greater discretion on the part of organizations' decision-making bodies in taking feedback into account (Dobusch et al., this volume).

Focusing on external factors, Dingwerth (2008) shows that in transnational governance organizations the structural advantages enjoyed by participants and stakeholders from certain regions, most prominently the Global North, result in significant disparities in the representation of interests from different regions and the dominance of a specific (Northern) framing of problems and solutions to them (see also Zajak, forthcoming). For instance, certain users and stakeholders, for example, from the Global North, may be better equipped with material resources, knowledge and social skills and have better access to feedback channels and therefore exercise greater influence on decision-making (Boström and Tamm Hallström, 2013; Botzem et al., this volume). Contextual factors have also been shown to significantly shape the impact and legitimacy of certification schemes and environmental and labor standards across the national and local jurisdictions in which they are applied (Bartley, 2010; Malets, 2015; Zajak, 2017).

Thus, the usage of feedback channels is shaped by both the design and organization of feedback channels and external contextual factors. Nonetheless, it is also necessary to consider the responsiveness of governance organizations to feedback.

\section{Responsiveness of governance organizations}

Governance organizations' response to the feedback they receive from regulatory addressees, affected groups and broader publics may range from taking no action to active engagement, including the revision of transnational rules, the modification of organizational procedures and structures and other adjustments. Building on Oliver's (1991) classification of organizational responses to institutional pressures, we distinguish between several potential responses on the part of governance organizations to feedback. Governance organizations may follow feedback closely and carefully implement the changes suggested by rule addressees, standards users and other stakeholders. They may also respond partially by negotiating feedback with these groups, accommodating some proposed changes while ignoring others. They may also take various actions to avoid any changes, for instance by justifying the existing rules and organizational structures. Calling into question or challenging feedback and attempting to manipulate or co-opt critics are also conceivable response strategies. Governance organizations may predominantly employ one of the strategies, but it is more likely that they will employ a combination of them.

The range of strategies that may be employed by governance organizations to deal with feedback suggests that 
organizational response does not necessarily lead to the changes suggested by rule addressees, affected groups or publics. Instead, the organizational response and resulting changes in rules and organizational structures vary across cases and need to be explored empirically in order to capture the complexity of organizational responsiveness and resulting organizational changes. For instance, the evaluation of the organizational response crucially depends on which regulatory addressee groups provide feedback (see above on the usage of feedback channels) and how important these groups are perceived to be by the governance organization in question. It is intuitive that feedback from influential stakeholders, such as donors, recognized experts or powerful watchdog organizations, may be perceived as more important than feedback from rule addressees and those affected by transnational rules, such as microcredit clients (Mader, forthcoming) or workers (Zajak, forthcoming). In other cases, organizations that depend on standard users as well as donors may be more responsive to feedback from the former than the latter.

\section{Typology of forms of recursivity}

Building on the analytical framework described in the previous section, we propose a typology of recursivity in governance organizations. We present it in the form of a conceptual map in a two-dimensional property space: the design and organization of recursivity, and the actual responsiveness (see Figure 1). For reasons of simplicity, in the second dimension we combine the actual use of feedback channels and the response of transnational governance organizations. Moreover, rather than being dichotomous, each dimension represents a continuum. The ways in which feedback channels are organized range from formal to informal recursive design. In between, various combinations may be located along this axis. Broadly speaking, high responsiveness refers to a significant usage of feedback channels and significant response by the organization. Low responsiveness describes insignificant usage of and response to feedback. Again, various combinations may be located along this second axis. Overall, the assessment of this dimension requires a more in-depth analysis of how feedback channels are used and how governance organizations respond to feedback along the lines described in the previous section and in the case studies. In fact, neither axis is intended to measure the qualities of governance organizations numerically, but to interpret the specific forms of recursivity displayed by different organizations and compare them with each other. This means that if more organizations were added to our analysis, the relative location of the various organizations on the conceptual map would probably change.

Based on these two dimensions, we distinguish between four ideal types of recursivity in governance organizations,

Figure 1. Typology of recursive governance organizations

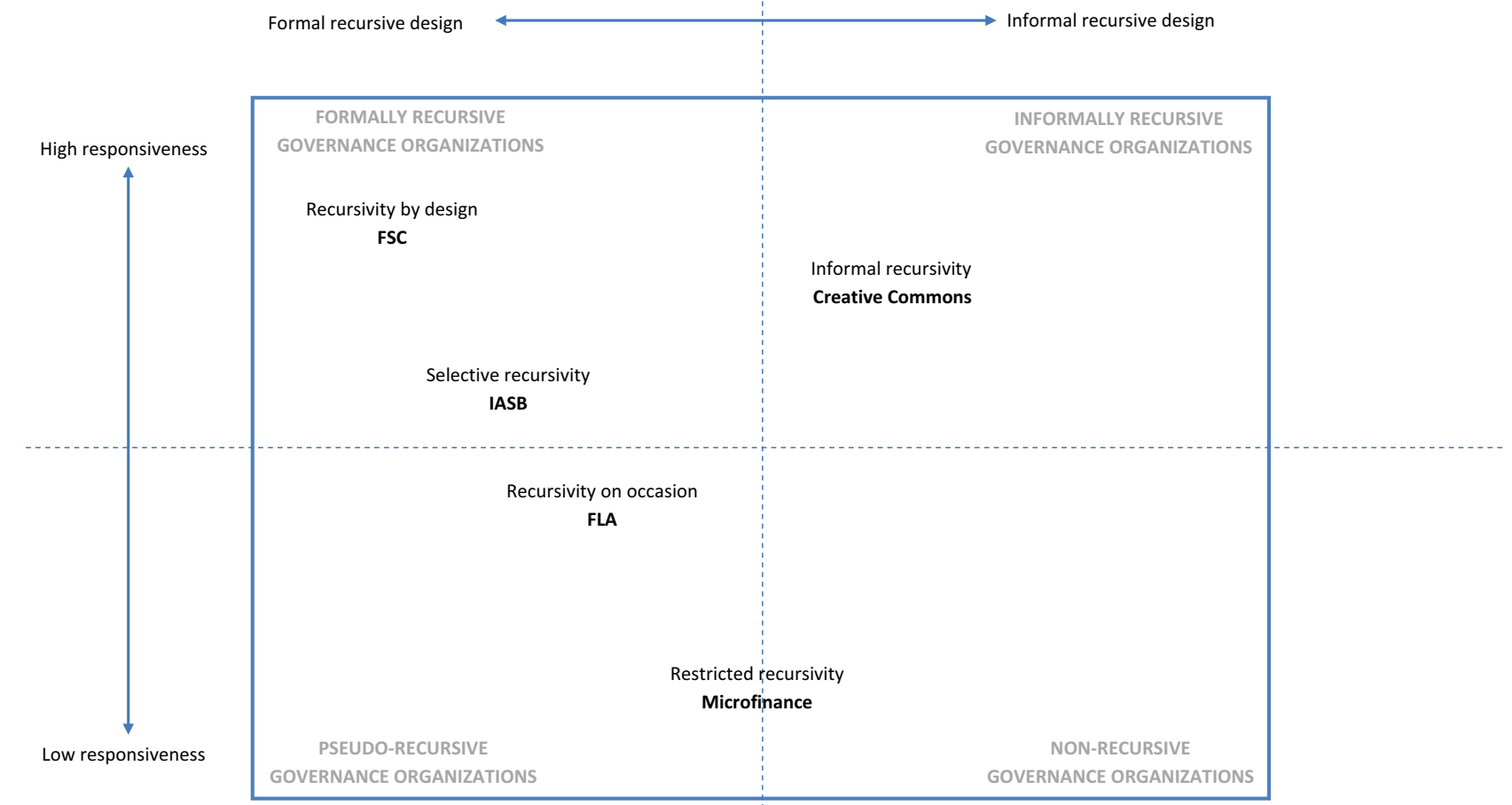


which are depicted at the extreme corners of the quadrants in Figure 1. Formally recursive governance organizations are characterized by a formal recursive design as well as intensive usage of and high responsiveness to feedback. Informally recursive governance organizations are characterized by the predominance of informal and inclusive feedback channels and relatively high responsiveness to feedback based on the leadership's informal commitment in the absence of formal accountability rules. Pseudo-responsive organizations have a formal feedback channel in place, but fail to respond to feedback in practice, or are rather selective in their response to feedback from key groups of regulatory addressees or groups affected by the rules. Finally, non-recursive governance organizations are not interested in encouraging feedback by designing feedback channels and rules to deal with feedback, nor do they respond to feedback. Non-recursive organizations are likely to be very rare in transnational governance, since the voluntary character of their regulation seems to require at least some interaction with their addressees and other stakeholder groups.

In order to demonstrate how we apply our analytical framework, we briefly summarize the contributions in this special section and locate them on our conceptual map in the next section.

\section{Contributions and key findings}

Two cases analyzed in our special section - the Forest Stewardship Council (FSC) and the International Accounting Standards Board (IASB) - represent formally recursive governance organizations. Malets (this volume) analyzes recursivity in the FSC, a transnational standard setting, certification and accreditation scheme for responsible forest management and supply chains in the forest sector. She traces the historical development of recursive processes in the FSC and suggests that over time the FSC, a membership organization from the start, has developed a formal recursive design, that is, an extensive set of organizational structures and procedures encouraging and organizing feedback, including an evaluation and monitoring system and a dispute settlement system. In addition, she emphasizes meta-standardization (i.e. the development of standards for standard setting organizations) as a driver of recursivity in the FSC. As a result, she refers to the FSC as a case of 'recursivity by organizational design'. She demonstrates how stakeholder and user feedback flows into the organization's decision-making and shapes its organizational procedures and forest management standards. In addition, she also shows how recursive stakeholder and user feedback processes and organizational responses occur at different governance levels - transnational, national and local. Building on her fieldwork in Russia, Malets illuminates how standard setting processes at the FSC level interact with implementation dynamics at the national level, emphasizing the repercussions of these interactions on global standard setting. Theoretically, she emphasizes the role of feedback in generating and reproducing the legitimacy of the FSC as a transnational governance organization. She argues that the conflicts and public critiques of the FSC, which are often viewed as sources of a legitimacy crisis and organizational fragility, can in fact be conceptualized as drivers of recursivity, rule adaptation and legitimacy building.

Botzem et al. (forthcoming) investigate the case of international accounting standards developed by the IASB, an organization that has developed a formal recursive design including a due process for public consultations. In line with existing literature, the authors show that opportunities for feedback through comment letters and representation in decision-making bodies are used unevenly, with large accounting firms, international organizations and actors from industrialized countries outweighing small and mediumsized companies, non-financial groups and actors from developing countries. Furthermore, decision-making on which comments to be included is often left to the technical committees and is not always transparent. Because of this, we locate the IASB below the FSC on the responsiveness axis on our conceptual map. More specifically, Botzem et al. analyze the causes for the underrepresentation of actors from the African continent in the IASB procedures. The authors identify a 'conceptual' mismatch, defined as a lack of fit between 'Western' assumptions underlying accounting standards and the context of implementation in developing countries, specifically in Sub-Saharan Africa. Therefore, the under-representation of African actors in the IASB procedures should not only be attributed to the lack of resources and expertise, but also to the lack of sensivity of the IASB's feedback procedures to the specific economic and social context conditions in developing countries. Botzem et al. refer to the coexistence of the IASB's responsiveness to some actors from developed countries and its apparent lack of capacity to meaningfully engage with actors from developing countries as selective recursivity. As the number of developing countries applying international accounting standards is continuously increasing, this lack of capacity is likely to impact on the credibility, legitimacy and effectiveness of transnational accounting standards in the medium term.

Dobusch et. al. (this volume) focus on a case of informally recursive governance organizations and investigate reciprocal links between rulemaking and user feedback in Creative Commons, a transnational private governance organization that has developed a set of open copyright licenses to govern the use of digital content. Dobusch et al. emphasize that in addition to several formal channels, Creative Commons collects feedback from its license users on its rules through several informal feedback channels, most prominently public mailing lists that were established to exchange information on the interpretation and application of licenses. Since informal channels have been at least equally important for making and revising licensing rules in Creative Commons (and thus constitute informal recursive design), Dobusch et al. refer to this type of recursivity as informal recursivity. By investigating regulatory conversations on public mailing lists, Dobusch et al. reveal several important implications for the informal articulation and processing of feedback in Creative Commons. First, although public mailing lists are open and anyone can participate in the 
discussion, conversations through informal feedback channels are dominated by more active communities of users. The authors refer to this problem as self-selection. Second, as a transnational private governance organization, Creative Commons cannot impose its licenses on users and depends on their voluntary adoption and political support. As a result, Creative Commons actively engages in regulatory conversations with its users in public mailing lists to maintain their support. At the same time, as a typical supporterbased organization, Creative Commons lacks clear internal rules that define how informal feedback is considered when decisions on rules are made. How decisions are made by the Creative Commons board is therefore not always transparent to or seen as legitimate by its users. Over time, Dobusch et al. argue, this is likely to create additional accountability demands on Creative Commons from its users.

The cases presented by Zajak (forthcoming) and Mader (forthcoming) represent pseudo-recursive governance organizations. Zajak analyzes one of the leading organizations in the transnational governance of labor rights, the Fair Labour Association (FLA), and focuses specifically on feedback from workers, a key group expected to be affected by transnational labor standards. She observes that most studies so far have focused on transnational governance organizations themselves and on the management practices of global brands, such as codes of conduct and auditing. This means, she argues, treating workers as a passive element of the governance system. Zajak shows that in terms of formal feedback channels, over time the FLA has become more recursive by introducing elements of formal recursive design, that is, a set of procedures and rules to collect and process feedback from workers, including worker surveys and complaint procedures. Yet, she suggests, these channels have been limited in terms of responsiveness to workers' feedback. In particular, she emphasizes that the FLA and factory managers retain interpretative authority over workers' complaints and the results of worker surveys. Since formal feedback channels, in particular the workers' complaint mechanism, have worked well in some cases, Zajak refers to the FLA's as a case of recursivity on occasion to emphasize its nonsystematic nature. Based on her empirical evidence from China, Zajak also stresses the importance of contextual structural factors limiting the ability of workers to actively use formal feedback channels designed by the FLA. Zajak also shows one potential way forward: grievance mediation between workers and factory management through local labor NGOs. She argues that this feedback channel appears to be context-specific, is more sensitive to the workers' interpretations of labor rights conflicts regarding working conditions at the factory level and provides workers with a voice in negotiating solutions with management. The need to integrate such channels into their procedures is a potentially important lesson for the FLA and other transnational labor governance organizations.

Mader (forthcoming) analyzes recursivity in the transnational governance of microfinance and focuses specifically on feedback from clients who borrow relatively small sums of money, or microcredits, from microfinance institutions
(MFIs). He traces the historical development of microfinance governance over several decades and argues that performance evaluation templates that have been developed for assessing MFIs' performance can be conceptualized as a formal feedback channel (i.e. an element of formal recursive design) that enables the pooling and processing of feedback. He shows, however, that these tools focus more on the financial sustainability and performance of individual MFIs than on their contribution to alleviating poverty and client satisfaction. Questions about the suitability of these tools for assessing the impact of microfinance on clients led to the development of assessment tools to monitor and audit MFIs' social performance. Mader also views these tools as a formal recursivity channel that generates information on measures taken by MFIs to increase their social performance, but points out that this channel also excludes clients and fails to capture the actual performance of microfinance and its impact on poverty: it only focuses on MFIs' internal procedures to monitor their social performance. He also reviews several initiatives launched by transnational NGOtype funders to create alternative assessment standards for socially responsible microfinance. According to Mader, while these initiatives have developed more effective tools for capturing clients' feedback and grievances, their impact in the microfinance field has been extremely limited. Based on this analysis, Mader argues that the formal feedback channels do not allow for the pooling and processing of information on the social impact of microfinance, which appears to block the revision of dominant transnational rules in this field. Mader refers to this constellation as restricted recursivity because it focuses on one type of information while ignoring others. Another of Mader's key findings is that the inability of microfinance governance organizations to pool and process clients' feedback leads to violent protests and suicides among debtors, which can be conceptualized as an emergent informal feedback channel and as clients' attempts to communicate their despair to MFIs, funders and the international organizations that govern this field.

\section{Conclusions}

The contributions in this special section display a great variety in recursivity across the transnational governance organizations studied in five policy fields. While each case study has a theoretical and empirical value of its own, a comparison of their results along the dimensions of our analytical framework provides additional insights into how recursivity by design and recursivity in action are linked to each other, and what impact recursivity has on the legitimacy of transnational governance schemes.

An important insight from this comparison is that having formal feedback procedures in place does not necessarily guarantee that these will also be used by those addressed and affect the rulemaking of transnational governance organizations. Neither does receiving feedback through such formal channels ensure that the organization will necessarily be responsive. For example, while the FSC and IASB both have formalized feedback procedures, the contributions by 
Malets and Botzem et al. suggest that these are used by a broader range of actors in the former than in the latter case, and the FSC has shown to be more responsive to critique and suggestions while the IASB has been more selective in its responsiveness.

Another noteworthy result is that transnational governance organizations with mainly informal procedures for feedback can still be equally or more responsive than others who have predominantly formalized procedures in place. The comparison between Creative Commons on the one hand, and the IASB, FLA and microfinance organizations on the other hand, indicate that responsiveness is as much a function of an informal system being open to feedback from a broad range of possible legitimacy communities as it is of the formality of its feedback and decision-making procedures.

Furthermore, a comparative analysis across the contributions suggests that transnational governance organizations that are neither formally nor informally highly responsive, or that show a high selectivity in their responsiveness, are likely to be challenged in their legitimacy claims by regulatory addressees or affected groups. These challenges can take different forms and may in turn lead to more recursivity. As suggested by Zajak, the FLA has over time responded to critics by introducing complaint channels. These, however, still do not take sufficient account of the expectations, capacities and context conditions of the affected workers, or the groups representing them, in ways that would allow them to voice their concerns. Furthermore, Mader's analysis of the microfinance crisis in India indicates that when faced with inadequate or absent feedback channels, negatively affected groups might move outside the organizational framework to articulate their protest on the streets.

In terms of potential avenues for future research, the contributions in this special section raise important questions about the role of the inclusiveness of recursive procedures for transnational governance organization's legitimacy claims. Inclusiveness refers to how openly governance organizations invite their regulatory addressees, affected groups and wider interested publics participate in the rulemaking, what support they offer them to provide feedback and how comprehensively they take responses from these audiences into account. The case comparison indicates that the studied transnational governance organizations perceive certain types of actors as particularly important for their operations. Furthermore, the contributions pose critical questions about which actors are likely to make use of which kinds of feedback channels, and which actors remain absent from the process despite being affected. Whereas the FSC and Creative Commons appear to be very open to who can provide feedback, other organizations present themselves as formally open, for example, the IASB or FLA, while their procedures in practice privilege certain groups over others because they require specific resources, knowledge or constitutional rights that are not available to actors in specific contexts. Botzem et al., for instance, argue that the IASB, despite its formal due process arrangements, is not very successful in organizing feedback from Sub-Saharan African states and therefore often does not address the needs of actors from these countries in its decision-making. The FLA is interested in workers' feedback on the improvement of labor conditions and protection of workers' rights, but also struggles to mobilize and consider feedback through its procedures. As Zajak (forthcoming) argues, workers have little direct voice in formal FLA feedback channels to date. In the governance of microfinance, MFls and key organizations setting rules for the whole sector are focused on financial performance of MFIs and provide templates and mechanisms to evaluate it, but have not developed adequate mechanisms for assessing and integrating the experience of microfinance clients, for instance in terms of poverty alleviation and empowerment (Mader, forthcoming).

As is also evident from the comparison above, the cases point out the need to consider how inclusive and open transnational rulemaking is in practice, not only on paper. This is broadly consistent with the literature on participation and inclusiveness in transnational governance: Several studies show, for instance, that the categorization of stakeholders is an essential and often contested instrument of inclusion in or exclusion from feedback channels (Dingwerth, 2008; Papadopoulos, 2013; Tamm Hallström and Boström, 2010). Moreover, in line with other studies (Voß and Freeman, 2016), our results point towards the structural features of feedback channels, including accessibility, the technicality of content and the time frame for response, through which organizations implicitly signal to potential audiences whether their feedback is desired or not. They also indicate fruitful avenues for researching recursivity in relation to accountability relations between transnational governance organizations on the one hand and those directly affected and those raising claims on their behalf (see Koenig-Archibugi and Macdonald 2012, p. 500, for 'beneficiary accountability' and 'accountability by proxy').

The case comparison also points towards the need to research more systematically organizational linkages across global, national and local levels in transnational governance schemes (see also Bartley and Egels-Zandén, 2016). The contributions in this special section indicate that cycles of rulemaking, implementation and revision are organized in different ways across these levels, both in design and practice. While some transnational governance organizations, in this special section represented by the FSC and CC, have set up national or regional affiliates, chapters or groups, others operate solely as global organizations, such as the FLA and microfinance organizations, while yet others, such as the IASB have linkages to national and European standard setters. A comparison across the contributions suggests that the presence (Dobusch et al., this volume; Malets, this volume) or absence (Botzem et al., forthcoming; Zajak, forthcoming) of national or local layers in the organization of recursivity may matter for the use of feedback channels and responsiveness of organizations. It provides support for the argument that transnational governance organizations can foster the collective organization of regulatory addressees and standard users at these levels. This, in turn, might support the articulation of problems and mismatches between 
global rules and standards, on the one hand, and local and regional conditions, on the other. More systematic research is required to identify how specific procedures for such localized feedback work in practice in various local, national and regional contexts.

Overall, the special section shows how comparing problems, sets of actors and feedback processes across governance schemes and implementation contexts can contribute to a better comprehension and systematization of different forms of recursive governance. Mapping different forms of feedback and building a typology of varieties of recursivity allows for a better informed evaluation of the accountability and legitimacy of transnational governance.

\section{The structure of the special section}

The special section consists of two parts published in two issues of Global Policy. This volume includes this introduction and articles by Malets (this volume) and Dobusch, et al., (this volume). The next issue includes articles by Botzem, et al. (forthcoming), Zajak (forthcoming) and Mader (forthcoming).

\section{Notes}

We are grateful for the support of the Max Planck Institute for the Study of Societies (MPIfG) for the language editing of all contributions published in this special section. Research for all contributions formed part of the MPIfG's 'Institution Building Across Borders' research group. We thank the participants of the Author Workshop at the MPIfG in September 2013; the Panel on 'Recursivity of Governance: Conceptualizing Global-local Interactions Across Issue Fields' at the ECPR's Standing Group on Regulatory Governance Conference in Barcelona in June 2014; and the Panel on 'Recursivity of Transnational Governance' at the SASE Annual Conference in Chicago in July 2014 for helpful comments on earlier versions of the papers. We also thank the Global Policy editorial team for their support.

1. For example, International Financial Reporting Standards were developed as voluntary standards but have now been recognized by the European Union and many states worldwide as binding regulatory frameworks for public companies' financial reports (Botzem, 2012; Nölke, 2015).

2. Recent contributions to this literature include a series of studies on the role that regulatory intermediaries play between regulators and regulatory targets (see special issue edited by Abbott et al., 2017).

3. Membership-based organizations provide their members with welldefined decision-making and consultation rights, while supporterbased organizations rely on the acceptance and support of external audiences, for instance transnational standard users and other stakeholders, but as non-membership organizations they do not provide them with clear decision-making powers (Anheier and Themudo, 2002).

\section{References}

Abbott, K. W., Levi-Faur, D. and Snidal, D. (2017) 'Introducing Regulatory Intermediaries', The Annals of the Americal Academy of Political and Social Sciences, 670 (1), pp. 6-13.

Anheier, H. and Themudo, N. (2002) 'Organizational Forms of Global Civil Society: Implications of Going Global', in M. Glasius, M. Kaldor, \&
H. K. Anheier (eds.), Global Civil Society 2002. Oxford: Oxford University Press, pp. 191-216.

Bartley, T. (2010) 'Transnational Private Regulation in Practice: The Limits of Forest and Labor Standards Certification in Indonesia', Business and Politics, 12 (3), Article 7.

Bartley, T. and Egels-Zandén, N. (2016) 'Beyond Decoupling: Unions and the Leveraging of Corporate Social Responsibility in Indonesia', Socio-Economic Review, 14 (2), pp. 231-255.

Black, J. (2008) 'Constructing and Contesting Legitimacy and Accountability in Polycentric Regulatory Regimes', Regulation \& Governance, 2 (2), pp. 137-164.

Boström, M. and Tamm Hallström, K. (2013) 'Global Multi-stakeholder Standard-setters: How Fragile Are They?', Journal of Global Ethics, 9 (1), pp. 93-110.

Botzem, S. (2012) The Politics of Accounting Regulation: Organizing Transnational Standard Setting in Financial Reporting. Cheltenham: Edward Elgar.

Botzem, S. and Dobusch, L. (2012) 'Standardization Cycles: A Process Perspective on the Formation and Diffusion of Transnational Standards', Organization Studies, 33 (5-6), pp. 737-762.

Botzem, S., Quack, S. and Zori, S. (forthcoming). 'International Accounting Standards in Africa: Selective Recursivity for the 'Happy Few'?' Global Policy.

Calliess, G. P. and Zumbansen, P. (2010) Rough Consensus and Running Code. Oxford: Hart Publishing.

De Búrca, G. (2015) Human Rights Experimentalism. Max Weber Lecture Series 2015/02 [online]. Available from: http://cadmus.eui.eu/bitstrea $\mathrm{m} /$ handle/1814/38110/MWP_LS_DeBurca_2015_02.pdf?sequence= 1\&isAllowed=y [Accessed 10 May 2017].

Dingwerth, K. (2008) 'North-South Parity in Global Governance: The Affirmative Procedures of the Forest Stewardship Council', Global Governance, 14 (1), pp. 53-71.

Djelic, M.-L. and Sahlin-Andersson, K. (eds.) (2006) Transnational Governance: Institutional Dynamics of Regulation. Cambridge: Cambridge University Press.

Dobusch, L., Lang, M. and Quack, S. (2017) 'Open to Feedback? Formal and Informal Recursivity in Creative Commons' Transnational Standard-Setting', Global Policy.

Green, J. (2014) Rethinking Private Authority: Agents and Entrepreneurs in Global Environmental Governance. Princeton, NJ: Princeton University Press.

Greenwood, R. and Hinings, C. R. (1993) 'Understanding Strategic Change: The Contribution of Archetypes', Academy of Management Journal, 36 (5), pp. 1052-1081.

Gulati, R. and Puranam, P. (2009) 'Renewal through Reorganization: The Value of Inconsistencies between Formal and Informal Organization', Organization Science, 20 (2), pp. 422-440.

Hale, T. and Held, D. (2010) 'Editors' Introduction: Mapping Changes in Transnational Governance', in T. Hale and D. Held (eds.), Handbook of Transnational Governance Innovations. London: Polity, pp. 1-36.

Halliday, T. C. (2009) 'Recursivity of Normmaking: A Sociolegal Agenda', Annual Review of Law and Social Science, 5, pp. 263-289.

Halliday, T. C. and Carruthers, B. G. (2007) 'The Recursivity of Law: Global Norm Making and National Lawmaking in the Globalization of Corporate Insolvency Regimes', American Journal of Sociology, 112 (4), pp. 1135-1202.

Halliday, T. C. and Carruthers, B. G. (2009) Bankrupt: Global Lawmaking and Systemic Financial Crisis. Stanford, CA: Stanford University Press.

Halliday, T. C. and Shaffer, G. (eds.) (2015) Transnational Legal Orders. Cambridge: Cambridge University Press.

Koenig-Archibugi, M. and Macdonald, K. (2012) 'Accountability-by-proxy in Transnational Non-state Governance', Governance, 26 (3), pp. 499-522.

Koppel, J. G. S. (2010) World Rule: Accountability, Legitimacy, and the Design of Global Governance. Chicago, IL: University of Chicago Press. 
Loconto, A. and Fouilleux, E. (2014) 'Politics of Private Regulation: ISEAL and the Shaping of Transnational Sustainability Governance', Regulation \& Governance, 8 (2), pp. 166-185.

Mader, P. (forthcoming) 'How Much Voice for Borrowers? Restricted Feedback and Recursivity in Microfinance', Global Policy.

Malets, O. (2015) 'When Transnational Standards Hit the Ground: Domestic Regulations, Compliance Assessment and Forest Certification in Russia', Journal of Environmental Policy and Planning, 17 (3), pp. 332-359.

Malets, O. (2017) 'Recursivity by Organizational Design: The Case of the Forest Stewardship Council', Global Policy. https://doi.org/10.1111/ 1758-5899.12413.

Marx, A. (2012) Private Transnational Governance, Legitimacy and Dispute Settlement: A Configurational Analysis of Private Certification Systems. Working Paper 92. Leuven: Leuven Center for Global Governance Studies.

Marx, A. (2014) 'Legitimacy, Institutional Design, and Dispute Settlement: The Case of Eco-Certification Systems', Globalizations, 11 (3), pp. 401-416.

Nölke, A. (2015) 'Rising Powers and Transnational Private Governance: The International Accounting Standards Board', in D. Lesage and T. van de Graaf (eds.), Rising Powers and Multilateral Institutions. Houndmills: Palgrave Macmillan, pp. 96-116.

Oliver, C. (1991) 'Strategic Responses to Institutional Processes', Academy of Management Review, 16 (1), pp. 145-179.

Overdevest, C. and Zeitlin, J. (2014) 'Assembling an Experimentalist Regime: Transnational Governance Interactions in the Forest Sector', Regulation \& Governance, 8 (1), pp. 22-48.

Peters, A., Koechlin, L., Förster, T. and Zinkernagel, G. F. (eds.) (2009) Non-state Actors as Standard Setters. Cambridge: Cambridge University Press.

Papadopoulos, Y. (2013) The Challenge of Transnational Private Governance: Evaluating Authorization, Representation, and Accountability. LIEPP Working Paper 8. Paris: SciencePo
Quack, S. (2007) 'Legal Professionals and Transnational Law-making: A Case of Distributed Agency', Organization, 14 (5), pp. 643-666.

Sabel, C. F. and Zeitlin, J. (2012) 'Experimentalist Governance', in D. LeviFaur (ed.), The Oxford Handbook of Governance. Oxford: Oxford University Press, pp. 169-183.

Tamm Hallström, K. (2004) Organizing International Standardization: ISO and the IASC in Quest for Authority. Cheltenham: Edward Elgar.

Tamm Hallström, K. and Boström, M. (2010) Transnational Multistakeholder Standardization: Organizing Fragile Non-state Authority. Cheltenham: Edward Elgar.

Voß, J. P. and Freeman, R. (eds.) (2016) Knowing Governance: The Epistemic Construction of Political Order. Houndmills: Palgrave Macmillan.

Zajak, S. (2017) Transnational Activism, Global Labor Governance, and China. Houndmills: Palgrave Macmillan.

Zajak, S. (forthcoming) 'Recursivity and Workers' Voice: Channels for Workers' Voice in the Transnational Governance of Labour Rights?', Global Policy.

\section{Author Information}

Olga Malets is senior research associate at the Institute for Environmental Governance, University of Freiburg. Her interests focus on sustainability politics and transnational governance in global resourcebased sectors, including the forest industry and agriculture.

Sigrid Quack is Professor of Sociology with a focus on comparative and transnational perspectives at the University of Duisburg-Essen. She is a Senior Research Fellow at the Centre for Global Cooperation Research and a member of the Research Priority Area Transformation of Contemporary Society, both at the University of Duisburg-Essen. Her main research interests encompass globalization, cross-border standard setting and the role of professional expertise in transnational governance. 